\title{
Mapping and interpretation of bed-reflection power from a surge-type polythermal glacier, Yukon, Canada
}

\author{
Nat J. WILSON, ${ }^{1}$ Gwenn E. FLOWERS, ${ }^{1}$ Laurent MINGO ${ }^{2}$ \\ ${ }^{1}$ Department of Earth Sciences, Simon Fraser University, Burnaby, British Columbia, Canada \\ E-mail: gflowers@sfu.ca \\ ${ }^{2}$ Blue System Integration Ltd, Vancouver, British Columbia, Canada
}

\begin{abstract}
Bed-reflection power (BRP) from ice-penetrating radar has been used to make inferences about subglacial conditions and processes, yet is subject to confounding influences, including englacial attenuation and bed geometry. We use radar data collected in 2008-11 from a polythermal glacier to compute BRP with the aim of relating BRP to basal conditions. We examine the relationship between raw BRP and ice thickness, apparent bed slope and thickness of the englacial scattering layer as a proxy for internal reflection power. We then analyze a corrected form of the BRP with a graph-segmentation algorithm to delineate areas of high and low reflection power. Low corrected BRP values are found near the glacier terminus where the bed is most likely to be cold, while high corrected BRP is found in the region thought to be undergoing a slow surge. We find a spatial correlation between high BRP and high values of subglacial hydraulic upstream area, suggestive of a hydrological control on BRP. Whereas in dominantly cold glaciers BRP seems to distinguish cold from temperate regions of the bed, BRP in a polythermal glacier with a substantial volume of temperate ice may be a more complex product of thermal and hydrological conditions.
\end{abstract}

KEYWORDS: glacier hydrology, glacier surges, mountain glaciers, radio-echo sounding, subglacial processes

\section{INTRODUCTION}

Bed-reflection power (BRP) has been used by practitioners of ice-penetrating radar to characterize the subglacial properties of ice sheets (e.g. Shabtaie and others, 1987; Bentley and others, 1998; Gades and others, 2000; Catania and others, 2003; Raymond and others, 2006; Jacobel and others, 2009; Langley and others, 2011) and glaciers (e.g. Copland and Sharp, 2001; Pattyn and others, 2005, 2009; Gades and others, 2012). Most of these studies have been conducted on ice masses with little temperate ice content, and high BRP has been linked to temperate basal conditions (e.g. Bentley and others, 1998; Gades and others, 2000; Catania and others, 2003), enhanced sliding (e.g. Pattyn and others, 2005, 2009) and the presence of subglacial water (e.g. Shabtaie and others, 1987; Copland and Sharp, 2001; Langley and others, 2011). Investigation of the temperate Black Rapids Glacier, Alaska, USA, by Gades and others (2012) is an exception to this, in which variations in BRP revealed more about the distribution of till at the bed than changes in basal hydrological conditions.

While the BRP measured at a radar receiver is assumed to be related to bed properties or hydrology, it is also affected by ice thickness, temperature and composition (e.g. Robin and others, 1969; Winebrenner and others, 2003; MacGregor and others, 2007; Matsuoka, 2011). It is common to deal with the ice-thickness effect by applying a correction, which may involve judiciously chosen subsets of the data (e.g. Gades and others, 2000). Interpretations related to basal conditions are then made on the basis of corrected BRP, either using interpolated maps of BRP (e.g. Copland and Sharp, 2001) or BRP extracted along a transect (e.g. Gades and others, 2000; Pattyn and others, 2009).

We use radar data from a surge-type polythermal glacier in Yukon, Canada, to investigate whether BRP provides insight into the present flow regime, which is characterized by high rates of basal motion over a well-defined region (De Paoli and Flowers, 2009). We first explore the relationship between raw BRP and variables that have been hypothesized or demonstrated to influence bed reflectivity. After applying an ice-thickness correction, we use an unsupervised imageclassification algorithm to segment the glacier into contiguous areas defined by similar BRP. Using an automatedsegmentation scheme both reduces the dimensionality of the dataset and avoids some sources of interpretation bias. We interpret the results in light of what is known about the thermal, hydrological and dynamical regime of the glacier.

\section{STUDY SITE}

The study glacier is located in a subarctic environment in the St Elias Mountains of Yukon (Fig. 1). It spans an elevation range of 1970-2960 m a.s.l., has an equilibrium-line altitude (ELA) of $\sim 2550 \mathrm{~m}$ a.s.l., occupies an area of $5.3 \mathrm{~km}^{2}$ and is up to $200 \mathrm{~m}$ thick. Using ice-penetrating radar and borehole thermometry, Wilson and others (2013) documented a polythermal structure in which temperate ice from the accumulation area gives way to cold ice near the glacier terminus, but were unable to determine precisely how far down-glacier temperate basal conditions extend. Forward (Flowers and others, 2011) and inverse (De Paoli and Flowers, 2009) modelling using surface velocity measurements suggests a flow regime dominated by sliding and/or bed deformation over the central region of the glacier which has been interpreted as a 'slow surge' (Frappé and Clarke, 2007). While this site was originally selected for a comparative glacier mass-balance study (e.g. MacDougall and Flowers, 2011), its current dynamics present an interesting opportunity to examine BRP in a polythermal 


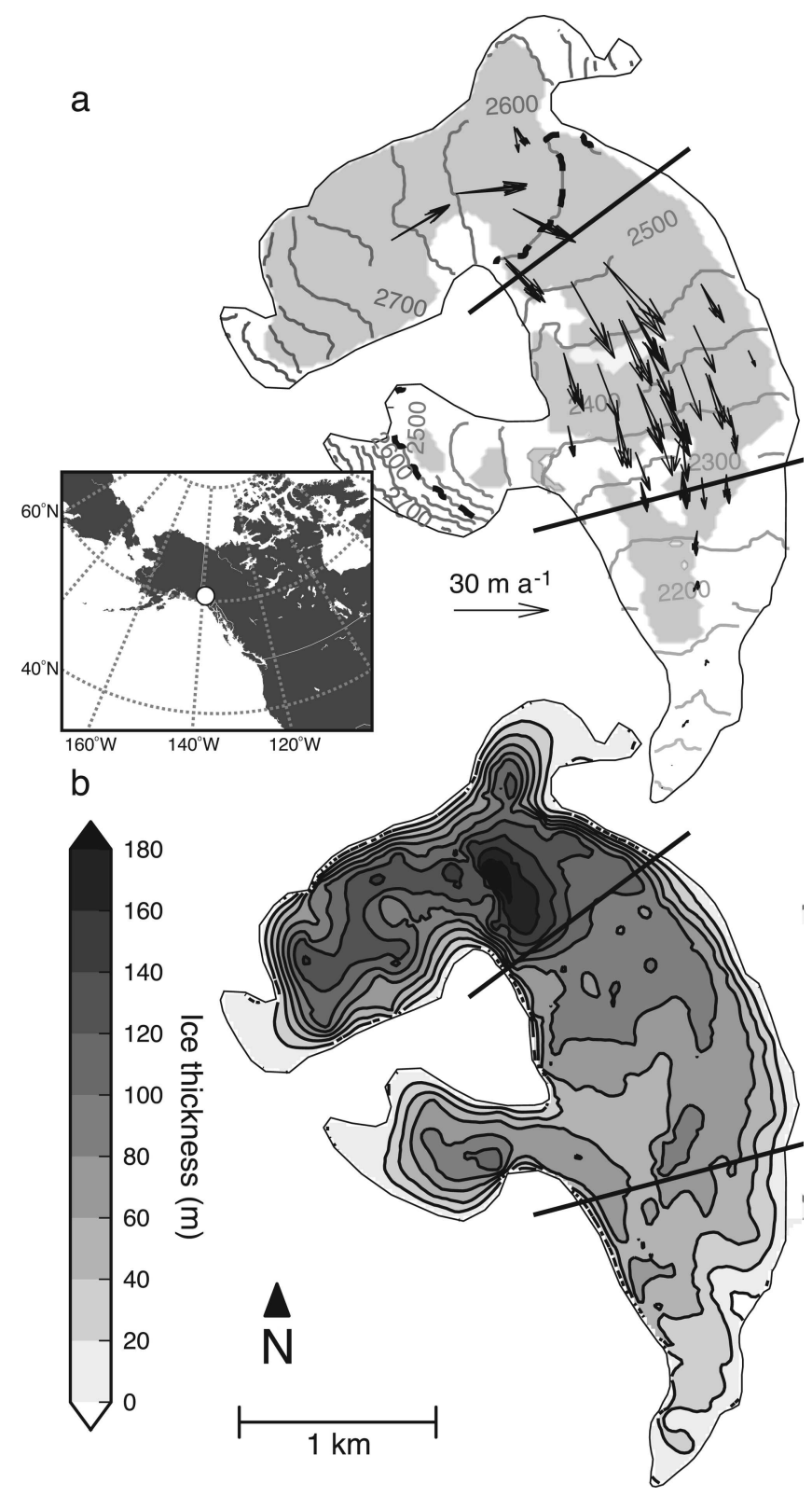

Fig. 1. Study area. Inset shows location (open circle) in the St Elias Mountains of southwest Yukon, Canada. (a) Contours of glacier surface elevation, with approximate ELA shown as a dashed line. Plan-view distribution of temperate ice from Wilson and others (2013) is shaded. Arrows indicate annual surface flow velocities measured at a network of stakes from 2006 to 2011. (b) Ice thickness. The approximate region of enhanced basal flow (De Paoli and Flowers, 2009) is delimited in (a) and (b) with straight bold lines.

glacier for the signatures of bed thermal state and hydrological regime.

\section{METHODS}

\section{Data collection and processing}

Ice-penetrating radar data were collected in spatially overlapping surveys in May of 2008, 2009 and 2011 with the system described by Mingo and Flowers (2010) (see Table 1). We use an impulse transmitter (Narod and Clarke, 1994) with resistively loaded dipole antennas of $10 \mathrm{MHz}$ centre frequency in the transmitting unit, while identical antennas and a computer-controlled digitizer comprise the receiving
Table 1. Radar system components and specifications for surveys conducted in 2008, 2009 and 2011

\begin{tabular}{|c|c|c|}
\hline Component & Type & Details \\
\hline Transmitter* & Impulse & $\begin{array}{c}1.1 \mathrm{kV}( \pm 550 \mathrm{~V}) \\
24 \mathrm{~kW} \text { peak power } \\
\text { Pulsed at } 512 \mathrm{~Hz}\end{array}$ \\
\hline & $\begin{array}{c}\text { NI-5133 } \\
\text { PicoScope } 4227\end{array}$ & $\begin{array}{l}8 \text { bit, } 50 \mathrm{MHz} \text { BW, } 100 \mathrm{MS} \mathrm{s}^{-1} \\
12 \text { bit, } 100 \mathrm{MHz} \text { BW, } 250 \mathrm{MS} \mathrm{s}^{-1}\end{array}$ \\
\hline Netbook & ASUS 900/901 & USB comm. with GPS \\
\hline GPS & $\begin{array}{l}\text { Rikaline } 6017 \\
\text { Holux } 213\end{array}$ & $\begin{array}{l}\leq 10 \mathrm{~m} \text { horizontal accuracy } \\
\leq 10 \mathrm{~m} \text { horizontal accuracy }\end{array}$ \\
\hline Specification & Description & Details \\
\hline Stacking & 50-256 traces & Software-based, capable of $>256$ \\
\hline Bandwidth & $20-100 \mathrm{MHz}$ & Depends on digitizer, settings \\
\hline Range resolution & $10-12 \mathrm{~m}$ & Based on reflected pulses, $10 \mathrm{MHz}$ \\
\hline
\end{tabular}

*Narod and Clarke (1994).

unit. Based on the width of reflected pulses, we estimate the range resolution to be $10-12 \mathrm{~m}$ (half the pulse width, assuming a wave speed in ice of $1.68 \times 10^{8} \mathrm{~m} \mathrm{~s}^{-1}$ ).

In 2008-09, we employed an 8-bit NI-5133 digitizer, which has a $50 \mathrm{MHz}$ bandwidth for all but the lowest voltage input range. At the lowest input range, corresponding to the highest receiver gain, bandwidth is reduced to $35 \mathrm{MHz}$. In 2011 we used a $100 \mathrm{MHz}$ bandwidth 12-bit Pico-4227 digitizer to accommodate antennas with higher centre frequencies $(>35 \mathrm{MHz})$ which we used for other purposes (Wilson and others, 2013). The Pico-4227's 12-bit analog-todigital converter allowed a significant increase in the lowest detectable voltage ('noise floor'): $24 \mu \mathrm{V}$ compared with $156 \mu \mathrm{V}$ for the 8-bit digitizer. For both digitizers, the optimum device input range was used to calculate the minimum detection level: $100 \mathrm{mV}$ peak-to-peak and $40 \mathrm{mV}$ peak-to-peak, respectively for the Pico-4227 and the NI5133. The ability of the Pico-4227 to store all traces within a given stack in its onboard memory before transferring data to the computer, in contrast to the NI-5133 which must transfer each trace individually, in principle increases the horizontal resolution in the survey direction by reducing the distance travelled between stacks.

A USB-powered wide area augmentation system (WAAS)capable GPS receiver with NMEA0183 data output provided geolocation. We mapped glacier surface elevations separately using real-time kinematic GPS. The radar data were processed using a de-mean (high-pass) filter and frequencywavenumber migration. Migration can improve the horizontal resolution of a diffraction-limited system to a theoretical value of $\lambda / 2$ (Welch and others, 1998); in our case $\lambda / 2=8.4 \mathrm{~m}$. No gain control was applied to the data, in order to avoid changing the BRP.

\section{Calculation and classification of BRP}

Following Gades and others (2000), we define BRP as

$$
\mathrm{BRP} \propto \frac{1}{t_{1}-t_{0}+1} \sum_{i=t_{0}}^{t_{1}} a_{i}^{2}
$$

where $a$ is the voltage measured at the receiving antenna, and sample numbers $t_{0}$ and $t_{1}$ together define a window 
along the fast time axis around the bed reflection. Gades and others (2000) use a summation window that is centred on the reflection waveform. Copland and Sharp (2001), by contrast, choose an asymmetric reflection window that begins $100 \mathrm{~ns}$ prior to the first peak in the reflected wavelet and continues $400 \mathrm{~ns}$ afterward. This larger window captures the full bed wavelet (Copland and Sharp, 2001), but potentially includes the effects of secondary reflections. We test a centred window chosen to fit the theoretical width of a single radar cycle $(100 \mathrm{~ns})$ as well as the asymmetric window used by Copland and Sharp (2001). The choice to operate on data that have undergone two-dimensional migration is expected to have ramifications for the calculation of BRP on small horizontal scales, but based on tests with unmigrated data does not greatly alter the pattern of BRP at spatial scales greater than $\sim 20 \mathrm{~m}$.

The reflections observed in 2011 are systematically brighter than those recorded in 2008-09. The transmitter and antennas were identical between all surveys, so differences in bed-reflection power could have arisen from (1) true temporal variations in BRP (e.g. Pattyn and others, 2009) between 2008-09 and 2011, (2) systematic differences in coupling between the antennas and the glacier between surveys or (3) differences in system power either transmitted or received. There is little reason to believe a systematic shift in bed character (and thus BRP) occurred between 2009 and 2011, or that coupling differed significantly between surveys, given the similar conditions under which they were conducted. Our metadata indicate that a $20 \mathrm{MHz}$ hardware-level filter was enabled $90 \%$ of the time with the NI-5133 digitizer, resulting in non-negligible signal attenuation at frequencies greater than $10 \mathrm{MHz}$. In an additional $5 \%$ of the data the lowest voltage input range was used, thus effectively reducing the bandwidth from 50 to $35 \mathrm{MHz}$. Given the broadband response of resistively loaded dipole antennas, and based on spectral analyses of sample radargrams with and without the filter enabled, we hypothesize that the differences in digitizer bandwidth and the use of the NI-5133 hardware filter are together largely responsible for the significant differences in BRP between the 2008-09 and 2011 datasets. Despite some uncorrected inconsistencies within 10\% of the 2008-09 dataset, we find that regions of the bed that appear systematically bright (high BRP) in our final results are independently bright in all years $(2008,2009,2011)$ when considered separately.

In light of the foregoing discussion, spatial consistency in BRP measurements from different surveys is substantially improved if we normalize BRP independently for 2008-09 and 2011. The 2011 survey covered all accessible regions of the glacier, as did the combined surveys of 2008-09; our approach to normalization should not, therefore, introduce spatial bias in the dataset. Alternative, but less successful, approaches tested include combining all data directly or normalizing by year rather than instrumental configuration. This normalization is done separately from correcting for attenuation through the ice column (described below).

We experiment with various methods of identifying spatial patterns in BRP. First we highlight regions above a prescribed threshold. In a second method, we partition the glacier into contiguous regions of distinct BRP by interpolating the data across the glacier bed and using a spectralclustering routine (e.g. von Luxburg, 2007) implemented as part of the scikit-learn project. Spectral clustering has been developed in the machine-learning community and permits a body of data to be divided into a prescribed number of clusters, $k$, by partitioning a similarity graph, $\mathcal{G}$, such that connections between clusters have low weight. Because the cluster selection is automatic, it avoids human bias in selecting data subsets. For spatial data such as BRP distribution, individual clusters are defined as contiguous spatial patches comprising pixels whose interconnections have higher weights (reflecting similar values of BRP in adjacent pixels) than the connections between pixels identified as separate clusters. The similarity graph, $\mathcal{G}$, encodes a representation of the connection weights between adjacent pixels in the dataset. There are numerous methods by which to partition the similarity graph into clusters. Von Luxburg (2007) gives a useful tutorial-based review of spectralclustering methods, while scikit-learn is a package that provides the spectral-clustering algorithms used here.

For this application, we first construct $\mathcal{G}$ by creating network connections between $50 \mathrm{~m} \times 50 \mathrm{~m}$ pixels in the gridded BRP map and adjacent pixels (von Neumann neighbourhood). We then apply weights, $W_{i}$, as a function of the BRP difference, $\triangle B R P$, between each pixel and the standard deviation across all of the connections in $\mathcal{G}$ :

$$
W_{i}=\exp \left(-\beta \frac{\Delta \mathrm{BRP}_{i}}{\Delta \mathrm{BRP}_{\mathrm{std}}}\right)
$$

with $i$ an integer referencing the image pixel (graph node) and $\beta=10$ a scaling parameter that controls the steepness of the weighting function. The weighting for small $\triangle B R P$ increases with the value of $\beta$.

\section{Empirical predictors of BRP}

We compare the BRP dataset to ice thickness, $h$, icethickness gradient, $|\partial h / \partial \ell|$, where $\ell$ is distance in the direction of maximum thickness gradient, and radar-scattering-layer thickness, $s$. Each of these comparisons is motivated by the hypothesis that raw BRP may be enhanced or diminished as a function of these variables. The existence of a functional relationship between ice thickness and radar wave energy is well known (e.g. Bogorodsky and others, 1985), while the ice-thickness gradient is the quantity that correctly represents apparent bed slope, or bed slope relative to the ice surface. Ice thickness is determined from the same radar data that are used to calculate BRP, and interpolated to create a digital model on a $20 \mathrm{~m} \times 20 \mathrm{~m}$ grid. Assuming that the glacier bed has some specular reflection characteristics, apparent bed slope (or ice-thickness gradient) would be expected to correlate with reduced BRP.

Losses due to internal scattering can be neglected in some settings (e.g. Pattyn and others, 2009), but it is not known whether they need to be considered in glaciers with significant volumes of temperate ice. We calculate scattering-layer thickness as a proxy for internal losses by mapping the upper surface of the radar-scattering layer observed over most of the glacier (Wilson and others, 2013) and assuming this layer extends to the bed. To identify the scattering layers within each transect, we first high-pass filter the data and then plot voltage magnitude to enhance the internal contrast within each section. The upper horizon of the scattering layer within a given radargram is then manually digitized (see Wilson and others, 2013, for details). Scattering-layer thickness is then defined as the depth from the scattering surface down to the bed reflection.

Finally, in an attempt to relate BRP to basal hydrological conditions (e.g. Copland and Sharp, 2001) we calculate 

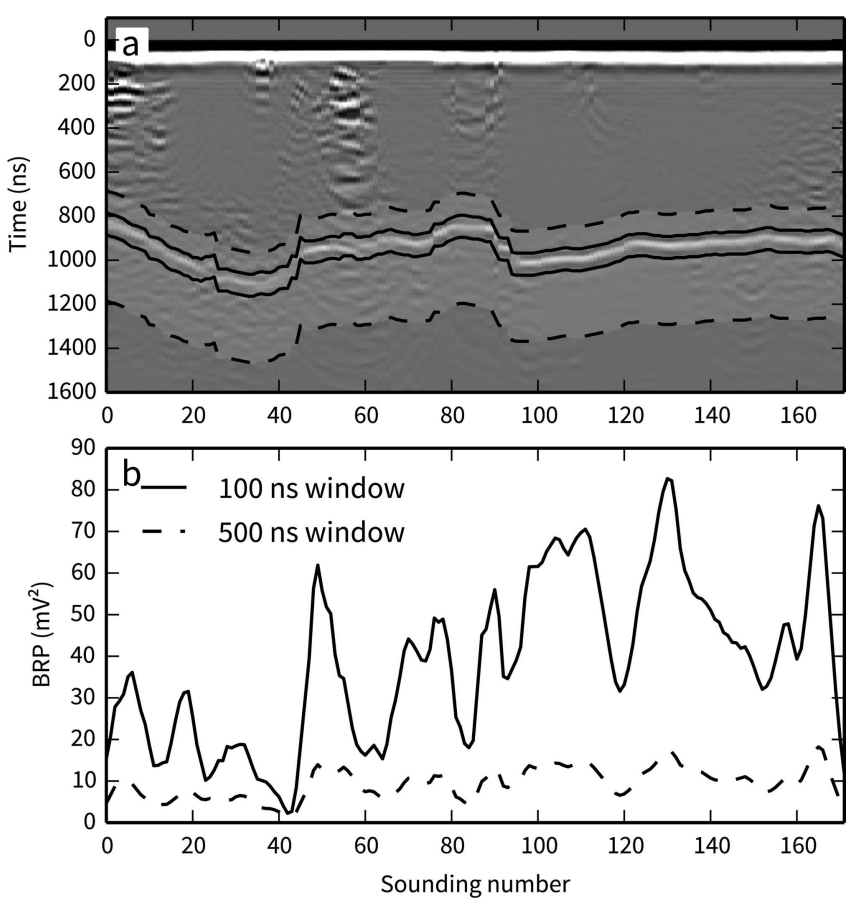

Fig. 2. Summation windows used to calculate BRP. (a) Summation windows shown on a sample radargram. (b) Corresponding BRP. Solid curve shows the summation window symmetric about the bed reflection and equal to the theoretical width of a single radar cycle. Dotted curve shows the asymmetric window used by Copland and Sharp (2001) on John Evans Glacier.

subglacial fluid potential (Shreve, 1972),

$$
\Phi=\rho_{\mathrm{w}} g z+f \rho_{\mathrm{i}} g h,
$$

with gravitational acceleration $g=9.8 \mathrm{~m} \mathrm{~s}^{-2}$, bed elevation $z$, densities of water $\rho_{\mathrm{w}}=1000 \mathrm{~kg} \mathrm{~m}^{-3}$ and of ice $\rho_{\mathrm{i}}=910 \mathrm{~kg} \mathrm{~m}^{-3}$ and $f=[0,1]$, where $f=1$ represents the hydrostatic assumption. We then compute the upstream area (UA) based on $\Phi$ with $0 \leq f \leq 1$, using an iterative pit-filling scheme applied to the fluid potential (Wang and Liu, 2006) followed by the D- $\infty$ flow-routing algorithm (Tarboton, 1997). The flow-routing algorithm computes the total area 'upstream' of each node, where that area is equal to the number of upstream pixels multiplied by pixel area. Fluid potential, $\Phi$, is used only to define flow direction, so the upstream area has dimensions of length-squared. To suppress the dominant downslope control on the upstream area and to reduce its sensitivity to uncertainties in the bed map, we compute

$$
U_{\mathrm{c}}=\log \left(\frac{\mathrm{UA}}{\mathrm{CA}}\right)
$$

where CA is a control area chosen such that UA/CA is a dimensionless quotient.

As a crude metric to evaluate the correlation between regions of high $\mathrm{BRP}$ and regions that may be preferentially connected to the subglacial drainage system, we calculate the mean of $U_{\mathrm{c}}$ over all pixels where average BRP is above a prescribed threshold and normalize this quantity, $U_{\mathrm{C}}^{+}$, by the mean over the entire glacier bed, $\overline{U_{\mathrm{c}}}$ :

$$
E=\frac{U_{\mathrm{c}}^{+}}{\overline{U_{\mathrm{c}}}}-1 \text {. }
$$

The dimensionless $E$ is then one possible measure of the increased likelihood of high BRP being measured over pixels with high upstream area. $E=0$ indicates no preferential association between high BRP and high $U_{\mathrm{c}}$. To compute $U_{\mathrm{c}}^{+}$, we identify locations with BRP values in the 70th percentile or above after BRP has been averaged at a scale of $50 \mathrm{~m} \times 50 \mathrm{~m}$.

To determine the robustness of $E$ as a correlation metric, we perform a suite of Monte Carlo simulations in which we randomly shuffle the gridded $B R P$ values in space and then recalculate $E$. By performing this operation many times, we can determine the expected variance in a randomly distributed field, which allows us to evaluate whether our real results exhibit a significantly greater correlation with upstream area than random distributions of BRP. We find that performing $3 \times 10^{4}$ simulations leads to a convergence of the variance toward a constant value.

\section{RESULTS AND DISCUSSION \\ Sensitivity of BRP to summation window}

The general structure of the BRP is similar using the different summation windows, with the larger (500 ns) window producing systematically lower BRP (Fig. 2). Although larger summation windows capture additional reflections that follow the chosen bed reflection, the $500 \mathrm{~ns}$ window is sufficiently large that calculated BRP is always lower than that computed with the $100 \mathrm{~ns}$ window. We adopt the $100 \mathrm{~ns}$ window for all subsequent calculations.

\section{Relationship of BRP to hypothesized predictors}

We find an approximately exponential relationship between BRP and ice thickness (Fig. 3a), although variability due to
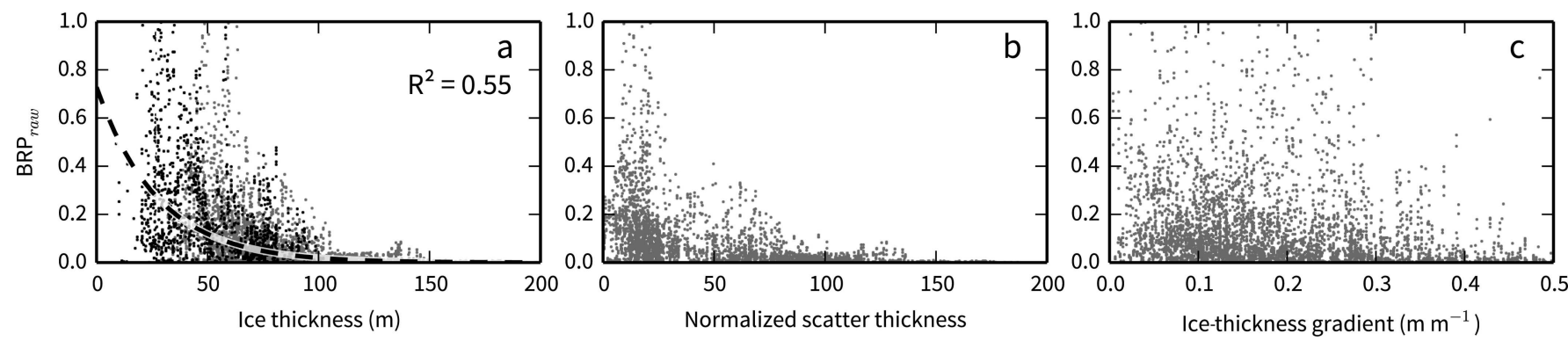

Fig. 3. Scatter plots of BRP and variables demonstrated or hypothesized to influence BRP measurements. (a) Ice thickness, $h$. Black dots represent a subset of the data where no internal scattering is observed. $R^{2}$ refers to the coefficient of determination. (b) Normalized thickness of internal scattering layer. (c) Magnitude of ice-thickness gradient, $|\partial h / \partial \ell|$ (apparent bed slope). 
other factors is high. The large degree of scatter is not surprising for a polythermal glacier with complex bed geometry: temperature variations and changes in bed angle and roughness will influence the attenuation rate of radar waves in ice and the energy reflected toward the receiving antennas, respectively. Correlation between BRP and variables other than ice thickness is much weaker. The thickness of the englacial scattering layer (Fig. 3b) appears to be correlated with BRP, but this is due to the correlation between ice thickness and BRP (Fig. 3a) and the correlation between ice thickness and scattering thickness (not shown). When BRP is corrected for ice thickness, the correlation with scattering thickness vanishes. BRP decreases only weakly with ice-thickness gradient (Fig. 3c) (cf. Copland and Sharp, 2001).

Performing a multiple regression of BRP on $h$ or any of the other variables discussed above does not meaningfully improve the predictability of BRP. We therefore conclude that of the variables tested, ice thickness alone provides the best avenue for a correction to the raw data. To characterize spatial variability in basal conditions in the next section, bed-reflection power is corrected by an exponential model intended to account for signal attenuation within the ice column due to absorption and reflection as well as geometric spreading (Gades and others, 2000):

$$
\mathrm{BRP}_{\text {corr }}=\frac{\mathrm{BRP}_{\text {raw }}}{\exp (b h)}
$$

with adjustable parameter, $b=-0.036 \mathrm{~m}^{-1}$, used to minimize squared residuals. This is equivalent to the fitting approach used by Gades and others (2000), with the exception that we use the entire dataset to derive the correction. Although $\mathrm{BRP}_{\text {corr }}$ remains a dimensionless scale of bed reflectivity, it can take on values greater than 1 .

We have experimented with modified correction techniques, such as selecting subsets of the data in deriving the ice-thickness correction on the basis of signal uniformity (e.g. Gades and others, 2000), proximity to the flowline (e.g. Pattyn and others, 2009) or low internal reflection power (e.g. Copland and Sharp, 2001). We find that these techniques do not yield better correlations between BRP and ice thickness for our data.

\section{Spatial pattern of corrected BRP}

High values of BRP are found preferentially in the central ablation area of the glacier (Fig. 4), while isolated lines of high BRP are also observed in the accumulation area. The heterogeneous nature of the BRP data makes manual delineation of the glacier into regions characterized by different bed reflectivity difficult and subjective. Analysis using spectral clustering also identifies a zone of high BRP in the central region of the glacier (Fig. 5), though its expression varies with the prescribed number of segments, $k$.

When the central region is partitioned into more than one segment (i.e. for $k \geq 8$ ) higher BRP values are found in the western half of this region, reflecting generally higher measured BRP there and a broader swath of high BRP values (Fig. 4).

The glacier terminus is consistently partitioned as a region of low BRP in this analysis. The paucity of data in certain areas (Fig. 4) suggests that caution should be used in interpreting Figure 5. For example, the uppermost glacier shows consistently high BRP, yet the sampling density in this area is relatively low. Likewise, the western tributary is an
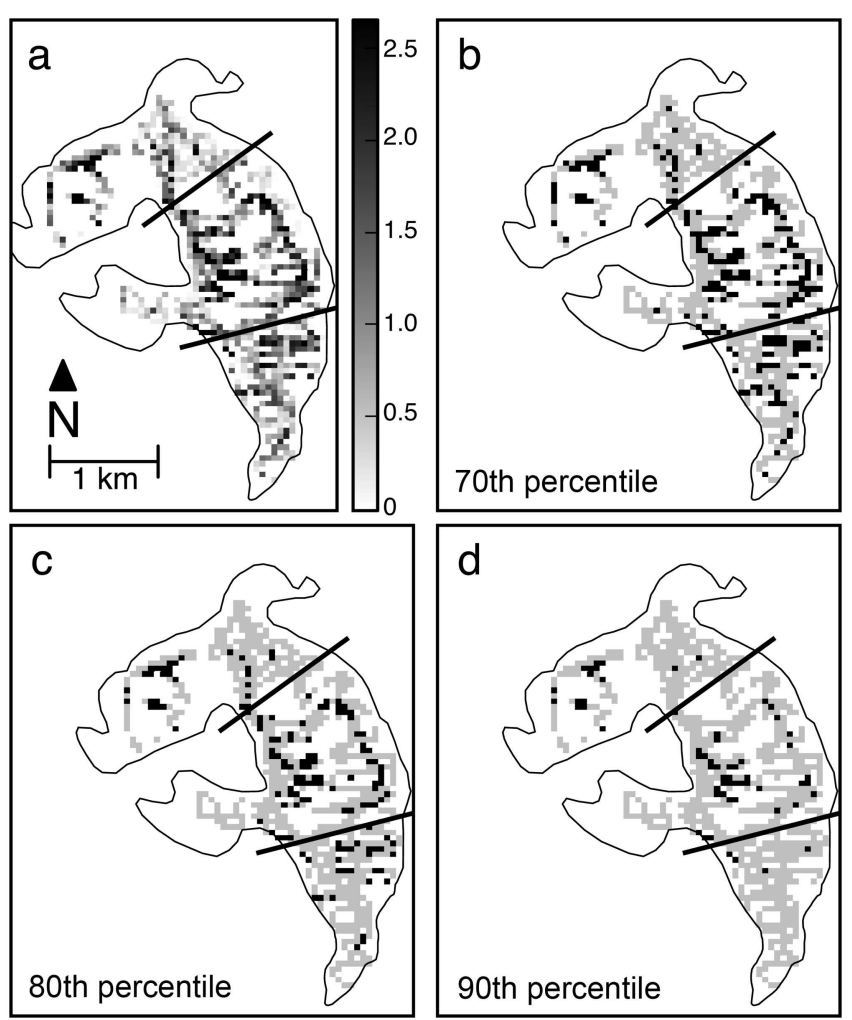

Fig. 4. BRP corrected for ice thickness. (a) All data averaged at a scale of $50 \mathrm{~m} \times 50 \mathrm{~m}$. Greyscale shows dimensionless values of $\mathrm{BRP}_{\text {corr }}$ from Eqn (6). (b) BRP higher than the 70th percentile shown in black with all other values in grey. (c) Same as (b) for the 80th percentile. (d) Same as (b) and (c) for the 90th percentile. The approximate region of enhanced basal flow is delimited in all panels with straight bold lines.

area of low BRP but also suffers from a low sampling density. Owing to the omnidirectional antenna radiation patterns in the across-track direction, across-track off-nadir reflections may also have some influence on calculated BRP that we are unable to correct for. This comprises an additional source of uncertainty that would express itself most strongly in the presence of steep across-track bed slopes. Inspection of the bed topography (Wilson, 2012) alongside the BRP maps suggests that steep slopes and high BRP coincide in several areas (e.g. in the uppermost reaches of the glacier). Other regions of higher BRP appear unrelated to steep bed slopes, including those in the western half of the central region of the glacier.

The use of differently sized summation windows creates small differences in the segmentation results; however, the general patterns reported above are persistent. Higher values of the parameter $\beta$ (Eqn (2)) increase the segmentation sensitivity to BRP variations over short distances. This, in turn, increases the likelihood that localized areas of anomalous BRP are separately classified. Small values of $\beta$ de-emphasize the importance of BRP magnitude relative to segment spatial continuity, resulting in more uniformly sized segments.

\section{Interpretation}

Generally low values of BRP near the glacier terminus are consistent with the thin $(<75 \mathrm{~m})$ and radar-transparent (cold) ice found there (Wilson and others, 2013). Surface flow speeds in this region are low, generally $\leq 5 \mathrm{~m} \mathrm{a}^{-1}$ (De Paoli and Flowers, 2009). The thin ice in this region permits rapid 

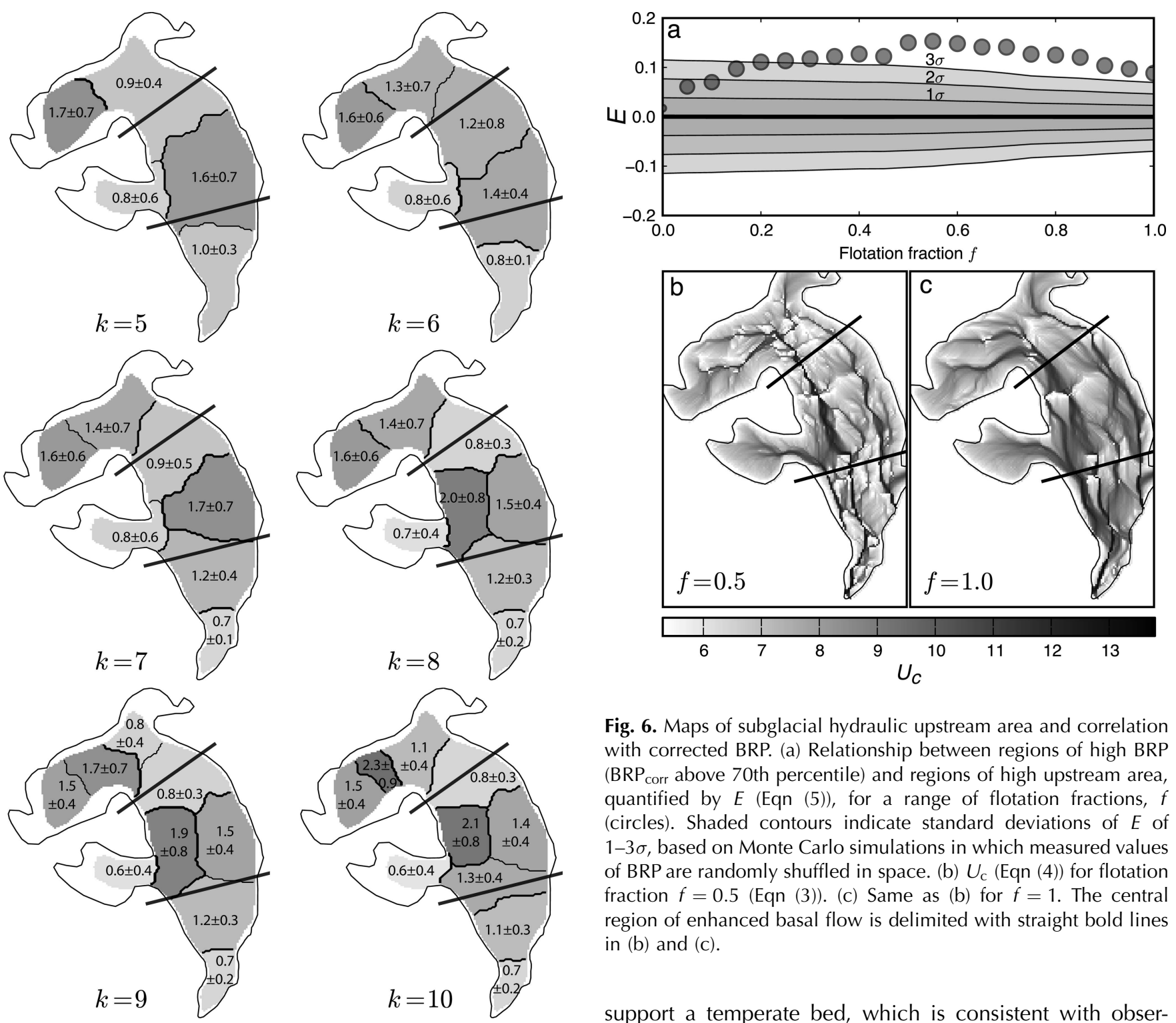

Fig. 6. Maps of subglacial hydraulic upstream area and correlation with corrected BRP. (a) Relationship between regions of high BRP $\left(\mathrm{BRP}_{\text {corr }}\right.$ above 70th percentile) and regions of high upstream area, quantified by $E$ (Eqn (5)), for a range of flotation fractions, $f$ (circles). Shaded contours indicate standard deviations of $E$ of $1-3 \sigma$, based on Monte Carlo simulations in which measured values of BRP are randomly shuffled in space. (b) $U_{\mathrm{c}}$ (Eqn (4)) for flotation fraction $f=0.5$ (Eqn (3)). (c) Same as (b) for $f=1$. The central region of enhanced basal flow is delimited with straight bold lines in (b) and (c).

Fig. 5. Classification results based on corrected BRP using spectral clustering. Numbers indicate the mean value and standard deviation of $\mathrm{BRP}_{\text {corr }}$ within the region. The approximate region of enhanced basal flow is delimited by straight bold lines.

heat loss to the atmosphere, driving the bed toward subfreezing temperatures (Wilson and Flowers, 2013; Wilson and others, 2013). During the melt season channelized drainage is observed at the glacier terminus, and a collapse feature in the glacier surface has revealed water flowing at the bed some distance $(\sim 500 \mathrm{~m})$ upstream of the terminus. These anecdotal observations, combined with the generally low BRP in this area, suggest that subglacial water near the terminus is confined to limited areas of the bed. Interannually persistent moulins over the lower kilometre of the glacier, where the ice is thin and deformation rates low, also argue for localization of basal water.

The western tributary, occupying a largely sheltered cirque, is a region characterized by low BRP. Generally low rates of surface ablation in this area (MacDougall and Flowers, 2011) would limit the influx of water and release of latent heat into the snowpack, and therefore support cold conditions over at least part of the glacier bed. High BRP in the uppermost reaches of the glacier (Fig. 5) seems to support a temperate bed, which is consistent with observations of englacial radar scattering throughout much of the ice column (Wilson and others, 2013).

The central region of the glacier delineated in Figures 1, 4 and 5 is characterized by a dynamic regime in which basal flow rates (sliding and/or substrate deformation) presently accommodate $50-100 \%$ of measured surface motion (De Paoli and Flowers, 2009). Forward modelling has shown this motion to be consistent with elevated basal water pressures (Flowers and others, 2011) facilitating basal lubrication. We might therefore expect higher values of BRP in this region, which has been interpreted to be surging (De Paoli and Flowers, 2009). Figures 4 and 5 provide some evidence for this, though in both analyses the onset of high BRP occurs down-glacier of the onset of high basal flow. Significant crevassing in this area is a source of radar clutter, which may depress the measured BRP, highlighting a potential shortcoming of our simple correction based on ice thickness alone. High values of BRP downstream of the region of high basal flow (Figs 4 and 5) may indicate temperate bed conditions below the transition identified as the 'surge front', consistent, at least in part, with the findings of Wilson and others (2013) (see shading in Fig. 1a).

An association between high BRP and enhanced basal motion could be corroborated by a correlation between high BRP and basal lubrication. Subglacial hydraulic upstream area (Fig. 6) may be a proxy for either enhanced or reduced 
basal lubrication, depending on the propensity for efficient drainage system development. Near the glacier terminus, the upstream area $\left(U_{c}\right.$ in Fig. 6$)$ is more likely to indicate favourable locations for channel development; further upstream, higher $U_{c}$ may indicate areas of preferential lubrication. The greater number and width of high upstream-area features in the western half of the central region suggest broader or more numerous subglacial pathways. This subglacial hydraulic geometry may contribute to the generally higher BRP in the western, compared to the eastern, region of the central glacier (Fig. 5; $k \geq 8$ ).

On a glacier-wide basis, Figure 6a shows that the correlation between high BRP and high $U_{\mathrm{c}}$, as described by the metric $E$ (Eqn (5)), is positive for any value of the flotation fraction, $f$. For $f \geq 0.35, E$ is above the $3 \sigma$ level for randomly generated results and we calculate the likelihood of a random realization of $E$ to be $1: 2500$. While upstream area is limited to describing highly simplified geometric controls on subglacial water flow, Figure 6a shows a statistically significant spatial coincidence of high BRP and high values of $U_{c}$, hinting at some relationship between BRP and basal lubrication. Whether BRP provides additional insight into the complex relationship between fast flow and subglacial conditions cannot be unambiguously established here (cf. Matsuoka, 2011). Despite this, it is intriguing to find elevated BRP where we know significant sliding and/or substrate deformation to be occurring.

\section{CONCLUSION}

We have calculated BRP from $10 \mathrm{MHz}$ ice-penetrating radar data covering most regions of a small surge-type polythermal glacier. While thermal and compositional variations are known to affect radar attenuation (e.g. Matsuoka, 2011), we did not find significant relationships between BRP and various proxies for englacial properties in the polythermal glacier investigated. Using an automated-segmentation scheme offers an objective means of partitioning the glacier into regions of high and low BRP, and provides a complement to the spatially averaged but uninterpolated pattern of BRP. For most values of the segmentation parameter, $k$, this analysis indicates a region of high BRP that overlaps a zone of high sliding/bed deformation previously interpreted as a slow surge (De Paoli and Flowers, 2009). High values of BRP were found elsewhere, where sliding/bed deformation plays a much smaller role but where temperate basal conditions are nevertheless expected. Glacier-wide correlations between high BRP and high values of subglacial hydraulic upstream area may be suggestive of a relationship between BRP and basal lubrication, though establishing the validity of such a relationship would require additional independent data. Though many of our results can be intuitively explained, the ambiguities that remain may allude to BRP being a better indicator of subglacial conditions for predominantly cold glaciers than for glaciers with a significant content of temperate ice.

\section{ACKNOWLEDGEMENTS}

This work was carried out with the permission of the Kluane First Nation, Parks Canada and the Yukon Territorial Government. The Polar Continental Shelf Program (PCSP) and the Kluane Lake Research Station (KLRS) provided support with field logistics. We are grateful for field assistance from numerous people, particularly Alex Jarosch and Flavien Beaud. Whistler-Blackcomb Resort facilitated field-testing of our radar equipment. Research funding was provided by the Natural Sciences and Engineering Research Council of Canada (NSERC), Simon Fraser University (SFU), the SFU Community Trust Endowment Fund, the Canada Research Chairs Program and the Canada Foundation for Innovation. Three anonymous reviewers made suggestions that led to an improved manuscript.

\section{REFERENCES}

Bentley CR, Lord N and Liu C (1998) Radar reflections reveal a wet bed beneath stagnant Ice Stream $C$ and a frozen bed beneath ridge BC, West Antarctica. J. Glaciol., 44(146), 149-156

Bogorodsky VV, Bentley CR and Gudmandsen PE (1985) Radioglaciology. D Reidel, Dordrecht

Catania GA, Conway HB, Gades AM, Raymond CF and Engelhardt $\mathrm{H}$ (2003) Bed reflectivity beneath inactive ice streams in West Antarctica. Ann. Glaciol., 36, 287-291 (doi: 10.3189/ $172756403781816310)$

Copland L and Sharp M (2001) Mapping thermal and hydrological conditions beneath a polythermal glacier with radio-echo sounding. J. Glaciol., 47(157), 232-242 (doi: 10.3189/ 172756501781832377)

De Paoli L and Flowers GE (2009) Dynamics of a small surge-type glacier investigated using one-dimensional geophysical inversion. J. Glaciol., 55(194), 1101-1112 (doi: 10.3189/ 002214309790794850)

Flowers GE, Roux N, Pimentel S and Schoof CG (2011) Present dynamics and future prognosis of a slowly surging glacier. Cryosphere, 5(1), 299-313 (doi: 10.5194/tc-5-299-2011)

Frappé T-P and Clarke GKC (2007) Slow surge of Trapridge Glacier, Yukon Territory, Canada. J. Geophys. Res., 112(F3), F03S32 (doi: 10.1029/2006JF000607)

Gades AM, Raymond CF, Conway H and Jacobel RW (2000) Bed properties of Siple Dome and adjacent ice streams, West Antarctica, inferred from radio-echo sounding measurements. J. Glaciol., 46(152), 88-94 (doi: 10.3189/ 172756500781833467)

Gades AM, Raymond CF and Conway HB (2012) Radio-echo probing of Black Rapids Glacier, Alaska, USA, during onset of melting and spring speed-up. J. Glaciol., 58(210), 713-724 (doi: 10.3189/2012JoG11J145)

Jacobel RW, Welch BC, Osterhouse D, Pettersson R and MacGregor JA (2009) Spatial variation of radar-derived basal conditions on Kamb Ice Stream, West Antarctica. Ann. Glaciol., 50(51), 10-16 (doi: 10.3189/172756409789097504)

Langley $\mathrm{K}$ and 8 others (2011) Recovery Lakes, East Antarctica: Radar assessment of sub-glacial water extent. Geophys. Res. Lett., 38(5), L05501 (doi: 10.1029/2010GL046094)

MacDougall AH and Flowers GE (2011) Spatial and temporal transferability of a distributed energy-balance glacier melt model. J. Climate, 24(202), 1480-1498 (doi: 10.1175/ 2010JCLI3821.1)

MacGregor JA, Winebrenner DP, Conway $H$, Matsuoka K, Mayewski PA and Clow GD (2007) Modeling englacial radar attenuation at Siple Dome, West Antarctica, using ice chemistry and temperature data. J. Geophys. Res., 112(F3), F03008 (doi: 10.1029/2006JF000717)

Matsuoka K (2011) Pitfalls in radar diagnosis of ice-sheet bed conditions: lessons from englacial attenuation models. Geophys. Res. Lett., 38(5), L05505 (doi: 10.1029/2010GL046205)

Mingo L and Flowers GE (2010) An integrated lightweight icepenetrating radar system. J. Glaciol., 56(198), 709-714 (doi: 10.3189/002214310793146179)

Narod BB and Clarke GKC (1994) Miniature high-power impulse transmitter for radio-echo sounding. J. Glaciol., 40(134), 190-194 
Pattyn F, Nolan M, Rabus B and Takahashi S (2005) Localized basal motion of a polythermal Arctic glacier: McCall Glacier, Alaska, USA. Ann. Glaciol., 40, 47-51 (doi: 10.3189/ 172756405781813537)

Pattyn F, Delcourt C, Samyn D, De Smedt B and Nolan M (2009) Bed properties and hydrological conditions underneath McCall Glacier, Alaska, USA. Ann. Glaciol., 50(51), 80-84 (doi: 10.3189/172756409789097559)

Raymond CF, Catania GA, Nereson N and Van der Veen CJ (2006) Bed radar reflectivity across the north margin of Whillans Ice Stream, West Antarctica, and implications for margin processes. J. Glaciol., 52(176), 3-10 (doi: 10.3189/172756506781828890)

Robin GdeQ, Evans S and Bailey JT (1969) Interpretation of radio echo sounding in polar ice sheets. Philos. Trans. R. Soc. London, Ser. A, 265(1166), 437-505 (doi: 10.1098/rsta.1969.0063)

Shabtaie S, Whillans IM and Bentley CR (1987) The morphology of Ice Streams A, B, and C, West Antarctica, and their environs. J. Geophys. Res., 92(B9), 8865-8883 (10.1029/ JB092iB09p08865)

Shreve RL (1972) Movement of water in glaciers. J. Glaciol., 11(62), 205-214

Tarboton DG (1997) A new method for the determination of flow directions and upslope areas in grid digital elevation models. Water Resour. Res., 33(2), 309-319 (doi: 10.1029/96WR03137)
Von Luxburg U (2007) A tutorial on spectral clustering. Stat. Comput., 17(4), 395-416 (doi: 10.1007/s11222-007-9033-z)

Wang L and Liu H (2006) An efficient method for identifying and filling surface depressions in digital elevation models for hydrologic analysis and modelling. Int. J. Geogr. Inf. Sci., 20(2), 193-213 (doi: 10.1080/13658810500433453)

Welch BC, Pfeffer WT, Harper JT and Humphrey NF (1998) Mapping subglacial surfaces of temperate valley glaciers by twopass migration of a radio-echo sounding survey. J. Glaciol., 44(146), 164-170

Wilson N (2012) Characterization and interpretation of polythermal structure in two subarctic glaciers. (Master's thesis, Simon Fraser University)

Wilson NJ and Flowers GE (2013) Environmental controls on the thermal structure of alpine glaciers. Cryosphere, 7(1), 167-182 (doi: 10.5194/tc-7-167-2013)

Wilson NJ, Flowers GE and Mingo L (2013) Comparison of thermal structure and evolution between neighboring subarctic glaciers. J. Geophys. Res., 118(3), 1443-1459 (doi: 10.1002/jgrf.20096)

Winebrenner DP, Smith BE, Catania GA, Conway HB and Raymond CF (2003) Radio-frequency attenuation beneath Siple Dome, West Antarctica, from wide-angle and profiling radar observations. Ann. Glaciol., 37, 226-232 (doi: 10.3189/ 172756403781815483) 